\title{
PENGARUH KEPEMIMPINAN DAN DISIPLIN KERJA TERHADAP KINERJA KARYAWAN PADA PT. DISTRIBUSI SENTRA JAYA
}

\author{
A. Junaedi Al Bagdadi ${ }^{1}$, N.Lilis Suryani ${ }^{2}$ \\ Fakultas Ekonomi, Universitas Pamulang \\ Email: dosen00437@unpam.ac.id
}

\begin{abstract}
Destination. This study aims to determine whether there is an influence or how much influence the variables of leadership and work discipline have on the performance of employees of PT. Distribution Center Jaya - South Tangerang.

Method. The method used in this study is a quantitative method, where the data collection technique used is the distribution of questionnaires and library data. The sample in this study were employees of PT. Distribution of Sentra Jaya - South Tangerang, totaling 65 people using the saturated sample method. The method used is multiple linear regression.

Results. From the results of data processing using SPSS 26, it was found that the Adjusted $R$ Square was 49.2\%. That is, the variables of Leadership and Work Discipline can explain the Performance variable by $49.2 \%$. The difference is influenced by other variables that are not used in this study. The results of this study conclude that partially, the variables of leadership and work discipline have a significant effect on the performance of employees of PT. Distribution Center Jaya - South Tangerang. Simultaneously, leadership and work discipline affect employee performance.
\end{abstract}

Implications. Companies must raise awareness of all employees so that they have the responsibility to complete the work. Companies must provide a comfortable workplace so that employees work sincerely.

Keywords: Leadership, Work Discipline, Employee Performance

\section{ABSTRAK}

Tujuan. Penelitian ini bertujuan untuk mengetahui adakah pengaruh atau seberapa besarkah pengaruh variabel kepemimpinan dan disiplin kerja terhadap kinerja karyawan PT. Distribusi Sentra Jaya - Tangerang Selatan.

Metode. Metode yang digunakan dalam penelitian ini adalah metode kuantitatif, dimana teknik pengumpulan data yang digunakan dengan penyebaran kuesioner. Sampel dalam penelitian ini adalah karyawan PT. Distribusi Sentra Jaya Tangerang Selatan yang berjumlah 65 orang dengan metode sampel jenuh. Metode yang digunakan adalah regresi linear berganda.

Hasil. Dari hasil pengolahan data menggunakan SPSS 26 didapati bahwa Adjusted R Square sebesar 49,2\%. Artinya, variabel Kepemimpinan dan Disiplin Kerja dapat menjelaskan variabel Kinerja sebesar 49,2\%. Selisihnya, dipengaruhi oleh variabel lain yang tidak digunakan dalam penelitian ini. Hasil dari penelitian ini menyimpulkan bahwa secara parsial, variabel kepemimpinan dan disiplin kerja berpengaruh signifikan terhadap 
kinerja karyawan PT. Distribusi Sentra Jaya - Tangerang Selatan. Secara simultan, kepemimpinan dan disiplin kerja berpengaruh terhadap Kinerja karyawan.

Implikasi. Perusahaan harus menumbuhkan kesadaran pada seluruh karyawan agar memiliki Tanggung jawab menyelesaiakan pekerjaan. Perusahaan harus memberikan tempat kerja yang nyaman agar karyawan bekerja ihklas.

Kata Kunci : Kepemimpinan, Disiplin Kerja, Kinerja Karyawan

\section{Pendahuluan}

Perusahaan secara umum adalah tempat terjadinya kegiatan produksi dan berkumpulnya semua faktor produksi. Pada dasarnya setiap perusahaan yang didirikan mempunyai harapan bahwa kelak dikemudian hari akan mengalami perkembangan yang pesat di dalam lingkup usaha dari perusahaannya dan menginginkan terciptanya kinerja yang tinggi dalam bidang pekerjaannya. Oleh karena itu keberadaaan suatu perusahaan yang berbentuk apapun baik dalam skala besar maupun kecil tidak terlepas dari unsur sumber daya manusia.

Berdasarkan kondisi perusahaan saat ini, di PT. Distribusi Sentra Jaya terdapat permasalahan yang berkaitan dengan kepemimpinan, disiplin kerja dan kinerja para karyawannya. Sebagai contoh pada kepemimpinan masih kurang percaya kepada karyawan dalam pemberian tugas-tugas yang seharusnya diberikan untuk bawahan, tidak berani menegur bawahan yang kurang sesuai, dalam berkomunikasi terhadap bawahan sering terjadi miss communication, dan tidak mau menerima kritikan dan saran dari bawahan. Sebagaimana hal ini dapat dilihat dari tabel hasil pra riset sebagai berikut :

Tabel 1. Hasil Pra riset Kepemimpinan PT. Distribusi Sentra Jaya

\begin{tabular}{|c|c|c|c|c|c|c|c|}
\hline \multirow[t]{2}{*}{ No } & \multirow[t]{2}{*}{ Unsur } & \multirow{2}{*}{ Target } & \multirow{2}{*}{$\begin{array}{l}\text { Jumlah } \\
\text { Karyawan }\end{array}$} & \multicolumn{2}{|c|}{$\begin{array}{c}\text { Penilaian } \\
\text { Karyawan }\end{array}$} & \multirow{2}{*}{ Persentase } & \multirow{2}{*}{ Ket } \\
\hline & & & & Ya & Tidak & & \\
\hline 1 & $\begin{array}{l}\text { Kejelasan dalam } \\
\text { memberikan tugas }\end{array}$ & $90 \%$ & 65 & 35 & 30 & $54 \%$ & Kurang \\
\hline 2 & $\begin{array}{ll}\text { Ketegasan } & \text { dalam } \\
\text { mengambil } & \\
\text { keputusan } & \end{array}$ & $90 \%$ & 65 & 33 & 32 & $51 \%$ & Kurang \\
\hline 3 & $\begin{array}{l}\text { Berkomunikasi } \\
\text { dengan bawahan } \\
\text { secara baik }\end{array}$ & $90 \%$ & 65 & 38 & 27 & $58 \%$ & Kurang \\
\hline 4 & $\begin{array}{l}\text { Mengayomi bawahan } \\
\text { sebagai mitra }\end{array}$ & $90 \%$ & 65 & 34 & 31 & $52 \%$ & Kurang \\
\hline 5 & $\begin{array}{l}\text { Mau menerima } \\
\text { kritikan dan saran }\end{array}$ & $90 \%$ & 65 & 32 & 33 & $49 \%$ & Buruk \\
\hline & Rata-rata & $90 \%$ & & & & $53 \%$ & Kurang \\
\hline
\end{tabular}

Sumber : PT. Distribusi Sentra Jaya (2021)

Berdasarkan tabel 1 di atas dapat diketahui terjadinya fenomena pada PT. Distribusi Sentra Jaya dimana rata-rata karyawan hanya menyerap sebesar $53 \%$ dari pertanyaan yang dibagikan. Nilai rata-rata tersebut didapatkan dari keseluruhan persentase data kepemimpinan. Dari data pra riset sebesar 53\% didasarkan pada keterangan yang tertera, dapat disimpulkan bahwa adanya penurunan terhadap kinerja karyawan PT. Distribusi Sentra Jaya.

Selain kepemimpinan yang berpengaruh terhadap kinerja adapun faktor lainnya yaitu disiplin kerja. Sebagai contoh disiplin kerja, masih adanya fluktuasi tingkat kehadiran karyawan. Dari segi ketidakhadiran baik berupa Alfa, Izin, dan sakit yang masih tinggi. Berikut ini adalah data tingkat kehadiran karyawan PT. Distribusi Sentra Jaya tahun 2017-2019: 
Tabel 2. Data Absensi Karyawan Periode Tahun 2017-2019

\begin{tabular}{|c|c|c|c|c|c|c|c|c|}
\hline \multirow{2}{*}{ Tahun } & \multirow{2}{*}{ Jumlah Pegawai } & \multicolumn{5}{|c|}{ Kriteria (Jumlah Karyawan) } & \multirow{2}{*}{ Jumlah } & \multirow{2}{*}{$\%$} \\
\cline { 3 - 8 } & & JHK & Cuti & Sakit & Izin & Alpa & Absensi & \\
\hline 2017 & 65 & 250 & 33 & 23 & 14 & 9 & 79 & $3,1 \%$ \\
\hline 2018 & 65 & 250 & 34 & 25 & 19 & 12 & 90 & $3,6 \%$ \\
\hline 2019 & 65 & 250 & 38 & 24 & 15 & 11 & 88 & $3,5 \%$ \\
\hline
\end{tabular}

Sumber : PT. Distribusi Sentra Jaya (2021)

Berdasarkan tabel 2 di atas menunjukkan tahun 2017 jumlah cuti, sakit, izin, dan alpa mendapat 79 absensi atau 3,1\% dari jumlah hari kerja (JHK). Tahun 2018 mengalami kenaikan menjadi 3,6\% kemudian pada tahun 2019 ada penurunan namun tidak signifikan yaitu sebesar $1 \%$ menjadi 3,5\%. Sehingga dapat disimpulkan absensi disana masih belum menunjukkan penurunan yang signifikan.

Masalah yang paling utama dalam organisasi perusahaan adalah masalah kinerja. Terkait dengan masalah kinerja karyawan PT. Distribusi Sentra Jaya, terlihat adanya penurunan kinerja yang tidak mencapai target. Berikut data penilaian kinerja karyawan Raw Material PT. Distribusi Sentra Jaya pada tahun 2017-2019:

Tabel 3. Data Penilaian Akhir Tahun Periode 2017-2019

\begin{tabular}{|c|l|c|c|c|c|}
\hline \multirow{2}{*}{ No } & \multirow{2}{*}{ Kriteria Penilaian Kerja } & \multirow{2}{*}{ Bobot (\%) } & \multicolumn{3}{|c|}{ Pencapaian } \\
\cline { 4 - 5 } & & 2017 & 2018 & 2019 \\
\hline 1 & Kedisiplinan & $20 \%$ & $17 \%$ & $15 \%$ & $14 \%$ \\
\hline 2 & Tanggung Jawab & $20 \%$ & $17 \%$ & $16 \%$ & $15 \%$ \\
\hline 3 & Kualitas Kerja & $20 \%$ & $16 \%$ & $15 \%$ & $13 \%$ \\
\hline 4 & Kuantitas Kerja & $20 \%$ & $17 \%$ & $16 \%$ & $14 \%$ \\
\hline 5 & Keterampilan Kerja & $20 \%$ & $16 \%$ & $15 \%$ & $15 \%$ \\
\hline \multicolumn{2}{r}{ Jumlah } & $100 \%$ & $83 \%$ & $77 \%$ & $71 \%$ \\
\hline
\end{tabular}

Sumber : PT. Distribusi Sentra Jaya (2021)

Berdasarkan tabel 3 dapat dilihat pencapaian kinerja dengan bobot target 100\% tidak tercapai secara maksimal selama 3 tahun. Dimana untuk tahun 2017 hanya mencapai bobot 83\% dan untuk tahun 2018 hanya mencapai bobot 77\% sedangkan untuk tahun 2019 hanya mencapai $71 \%$. Sehingga dapat disimpulkan bahwa penilaian kinerja karyawan baik dari segi kedisiplinan, tanggung jawab, kualitas kerja, kuantitas kerja, dan keterampilan kerja belum mencapai target perusahaan.

\section{Kajian Pustaka dan Hipotesis}

Kepemimpinan. Menurut Badeni (2013:2) "kepemimpinan dapat didefinisikan sebagai kemampuan seseorang untuk mempengaruhi suatu kelompok ke arah tercapainya tujuan". Adapun indikator kepemimpinan menurut Hasibuan (2014:170) sebagai berikut:

1) Keteladanan

Keteladanan sangat berperan dalam menentukan kedisiplinan karyawan karena pimpinan dijadikan teladan dan panutan oleh para bawahannya. Pimpinan harus memberi contoh yang baik, berdisiplin baik, jujur, adil, serta sesuai kata dan perbuatannya.

2) Kewibawaan

Kewibawaan adalah sebagai kekuatan yang memancar dalam diri seseorang karena kelebihan yang dimilikinya sehingga mendatangkan kepatuhan tanpa paksaan kepadanya.

3) Pendelegasian Tugas

Pendelegasian Tugas adalah suatu pelimpahan hak atau kekuasaan pimpinan terhadap bawahannya untuk melaksanakan tugas-tugasnya dengan sekaligus meminta pertanggung jawaban atas penyelesaiaan tugas-tugas tersebut. 
4) Pengambilan Keputusan

Pengambilan Keputusan adalah suatu proses penentuan keputusan yang terbaik dari sejumlah alternatif untuk melakukan aktivitas-aktivitas pada masa yang akan datang.

5) Motivasi

Motivasi maksudnya manajer memotivasi (merangsang) bawahannya dengan memberikan hadiah kepada mereka yang berproduktivitas di atas produktivitas standar. Dengan memotivasi positif, semangat kerja bawahan akan meningkat karena umumnya manusia senang menerima yang baik-baik saja.

Disiplin Kerja. Menurut Hasibuan (2014), kedisiplinan merupakan suatu keadaan dengan penuh kesadaran dan kepatuhan dalam menaati peraturan perusahaan dan norma sosial yang berlaku. Menurut Singodimendjo dalam Edy Sutrisno (2011:94) indikator-indikator yang mempengaruhi tingkat kedisiplinan karyawan suatu organisasi antara lain:

1) Taat aturan waktu

Dilihat dari jam masuk kerja, jam pulang, dan istirahat yang tepat waktu sesuai dengan aturan yang berlaku di perusahaan.

2) Taat aturan perusahaan

Peraturaan dasar tentang cara berpakaian, dan bertingkah laku dalam pekerjaan.

3) Taat aturan perilaku dalam pekerjaan

Ditunjukan dengan cara-cara melakukan pekerjaan-pekerjaan sesuai dengan jabatan, tugas dan tanggung jawab serta cara berhubungan dengan unit kerja lain.

4) Taat aturan lainnya di perusahaan

Menaati peraturan perundang-undangan dan prosedur perusahaan dalam perjanjian kerja atau kontrak kerja.

Kinerja. Menurut Edy Sutrisno (2012:22) "kinerja pegawai adalah prestasi yang diperoleh seseorang dalam melakukan tugas. Batasan dari pakar tersebut menekankan kinerja sebagai suatu proses untuk mencapai hasil-hasil tertentu yang direncanakan". Menurut Mangkunegara (2015 : 75) menyatakan bahwa indikator kinerja sebagai berikut :

a. Kualitas

Kualitas kerja adalah seberapa baik seorang karyawan mengerjakan apa yang seharusnya dikerjakan.

b. Kuantitas

Kuantitas kerja adalah seberapa lama seorang pegawai bekerja dalam satu harinya. Kuantitas kerja ini dapat dilihat dari kecepatan kerja setiap pegawai itu masing-masing.

c. Pelaksanaan tugas

Pelaksanaan Tugas adalah seberapa jauh karyawan mampu melakukan pekerjaannya dengan akurat atau tidak ada kesalahan.

d. Tanggung Jawab

Tanggung jawab terhadap pekerjaan adalah kesadaran akan kewajiban karyawan untuk melaksanakan pekerjaan yang diberikan perusahaan. Perusahaan harus benar-benar melakukan evaluasi dan pengkajian kembali terhadap setiap tugas dan tanggung jawab yang diberikan kepada karyawan.

e. Inisiatif

Merupakan adanya dari dalam diri anggota organisasi untuk melakuakn pekerjaan serta mengatasi masalah dalam pekerjaan tanpa menunggu perintah 


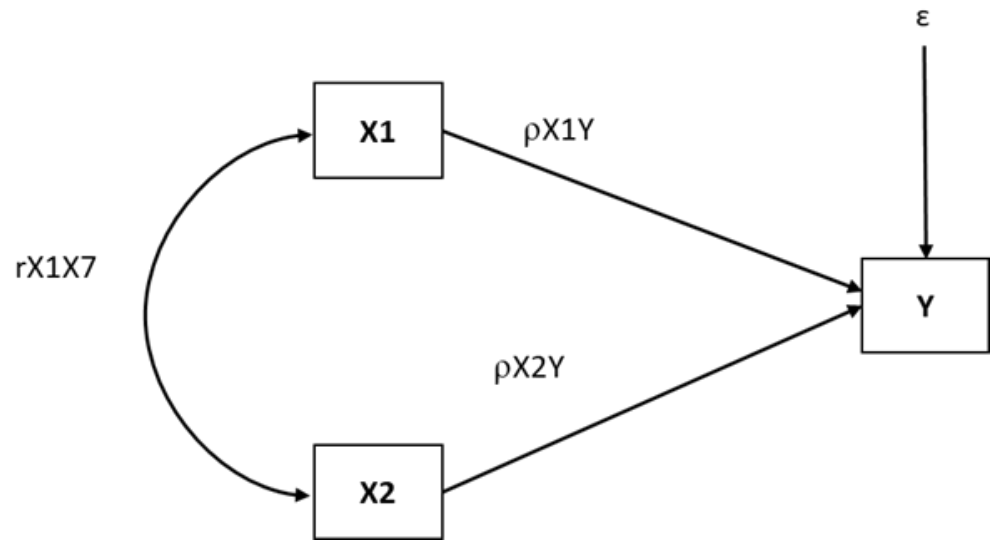

Gambar 1. Model Penelitian

\section{Hipotesis}

$\mathrm{H}_{01}$ : Tidak terdapat pengaruh Kepemimpinan terhadap kinerja karyawan PT. Distribusi Sentra Jaya.

$\mathrm{H}_{\mathrm{a} 1}$ : Terdapat pengaruh Kepemimpinan terhadap kinerja karyawan PT. Distribusi Sentra Jaya.

$\mathrm{H}_{02}$ : Tidak terdapat pengaruh Disiplin kerja terhadap kinerja karyawan PT. Distribusi Sentra Jaya.

$\mathrm{H}_{\mathrm{a} 2}$ : Terdapat pengaruh Disiplin kerja terhadap kinerja karyawan PT. Distribusi Sentra Jaya.

$\mathrm{H}_{03}$ : Tidak terdapat pengaruh Kepemimpinan dan Disiplin kerja terhadap kinerja karyawan PT. Distribusi Sentra Jaya.

$\mathrm{H}_{\mathrm{a} 3}$ : Terdapat pengaruh Kepemimpinan dan Disiplin kerja terhadap kinerja karyawan PT. Distribusi Sentra Jaya.

\section{Metode Penelitian}

Penelitian ini dilaksanakan pada bagian Raw Material PT. Distribusi Sentra Jaya Jl. Pahlawan Seribu lot 12A BSD - Tangerang Selatan 15326. Waktu penelitian ini berlangsung pada bulan Agustus 2020 s/d Januari 2021. Jumlah populasi dalam penelitian ini sebanyak 65 karyawan. Dengan menggunakan metode sampel jenuh peneliti mengambil sampel sebanyak 65 karyawan. Metode penelitian yang digunakan dalam penelitian ini adalah metode kuantitatif. Pengumpulan data dilakukan dengan menyebar kuesioner kepada karyawan. Analisis data yang digunakan dalam penelitian yaitu analisis jalur dengan menggunakan bantuan Software IBM SPSS (Statistical Program for Social Science) versi 26 for windows.

\section{Hasil Penelitian dan Pembahasan}

Dari hasil analisis dengan melihat karakteristik responden karyawan PT. Distribusi Sentra Jaya yang berjumlah 65 orang, maka dapat disimpulkan hal-hal sebagai berikut:

1) Berdasarkan data yang dikumpulkan oleh peneliti, telah didapatkan data jumlah karyawan/responden menurut jenis kelaminnya yaitu 24 orang berjenis kelamin perempuan (37\%) dan 41 orang berjenis kelamin laki-laki (63\%).

2) Berdasarkan data yang dikumpulkan oleh peneliti, telah didapatkan data jumlah karyawan/responden menurut usianya yaitu usia 20-30 tahun berjumlah 38 orang (58\%), usia 31-40 tahun berjumlah 17 orang (26\%), dan usia $>40$ tahun berjumlah 10 orang $(15 \%)$.

3) Berdasarkan data yang dikumpulkan oleh peneliti, telah didapatkan data jumlah karyawan/responden menurut pendidikannya yaitu SMA berjumlah 31 orang (48\%), D3 berjumlah 13 orang (20\%), dan S1 berjumlah 21 (32\%). 
Tabel 4. Hasil Uji Validitas

\begin{tabular}{|c|c|c|c|}
\hline Item Pernyataan & $\mathbf{R}_{\text {hitung }}$ & $\mathbf{R}_{\text {tabel }}$ & Kesimpulan \\
\hline \multicolumn{4}{|l|}{ Kepemimpinan } \\
\hline 1 & 0.372 & 0,30 & Valid \\
\hline 2 & 0.421 & 0,30 & Valid \\
\hline 3 & 0.407 & 0,30 & Valid \\
\hline 4 & 0.582 & 0,30 & Valid \\
\hline 5 & 0.797 & 0,30 & Valid \\
\hline 6 & 0.487 & 0,30 & Valid \\
\hline 7 & 0.726 & 0,30 & Valid \\
\hline 8 & 0.808 & 0,30 & Valid \\
\hline 9 & 0.788 & 0,30 & Valid \\
\hline 10 & 0.437 & 0,30 & Valid \\
\hline \multicolumn{4}{|l|}{ Disiplin Kerja } \\
\hline 1 & 0.345 & 0,30 & Valid \\
\hline 2 & 0.483 & 0,30 & Valid \\
\hline 3 & 0.337 & 0,30 & Valid \\
\hline 4 & 0.536 & 0,30 & Valid \\
\hline 5 & 0.534 & 0,30 & Valid \\
\hline 6 & 0.388 & 0,30 & Valid \\
\hline 7 & 0.637 & 0,30 & Valid \\
\hline 8 & 0.479 & 0,30 & Valid \\
\hline 9 & 0.418 & 0,30 & Valid \\
\hline 10 & 0.633 & 0,30 & Valid \\
\hline \multicolumn{4}{|l|}{ Kinerja Karyawan } \\
\hline 1 & 0.419 & 0,30 & Valid \\
\hline 2 & 0.600 & 0,30 & Valid \\
\hline 3 & 0.331 & 0,30 & Valid \\
\hline 4 & 0.505 & 0,30 & Valid \\
\hline 5 & 0.540 & 0,30 & Valid \\
\hline 6 & 0.529 & 0,30 & Valid \\
\hline 7 & 0.653 & 0,30 & Valid \\
\hline 8 & 0.622 & 0,30 & Valid \\
\hline 9 & 0.75 & 0,30 & Valid \\
\hline 10 & 0.501 & 0,30 & Valid \\
\hline
\end{tabular}

Sumber : Data Primer diolah (2021)

Dari data tabel di atas, diperoleh nilai rhitung lebih besar dari 0,30, maka semua item pernyataan dinyatakan valid. Untuk itu kuesioner yang digunakan layak untuk diolah sebagai data penelitian. 


\section{Pengujian Reliabilitas}

Tabel 5. Hasil Uji Reliabilitas

\begin{tabular}{|l|c|c|c|}
\hline \multicolumn{1}{|c|}{ Variabel } & $\begin{array}{c}\text { Nilai Cronbach's } \\
\text { Alpha }\end{array}$ & $\begin{array}{c}\text { Standar } \\
\text { Alpha }\end{array}$ & Keterangan \\
\hline Kepemimpinan (X1) & 0,779 & 0.6 & Reliabel \\
\hline Disiplin Kerja (X2) & 0,631 & 0.6 & Reliabel \\
\hline Kinerja (Y) & 0,740 & 0.6 & Reliabel \\
\hline
\end{tabular}

Sumber : Data Primer diolah (2021)

Berdasarkan tabel di atas, menunjukkan bahwa semua item pertanyaan variabel dinyatakan reliabel, hal itu dibuktikan dengan nilai Chronbatch Alpha kepemimpinan sebesar 0,779 , disiplin kerja sebesar 0,631 dan kinerja sebesar 0,740 yang nilainya $>0,60$.

\section{Uji Asumsi Klasik}

\section{Uji Normalitas}

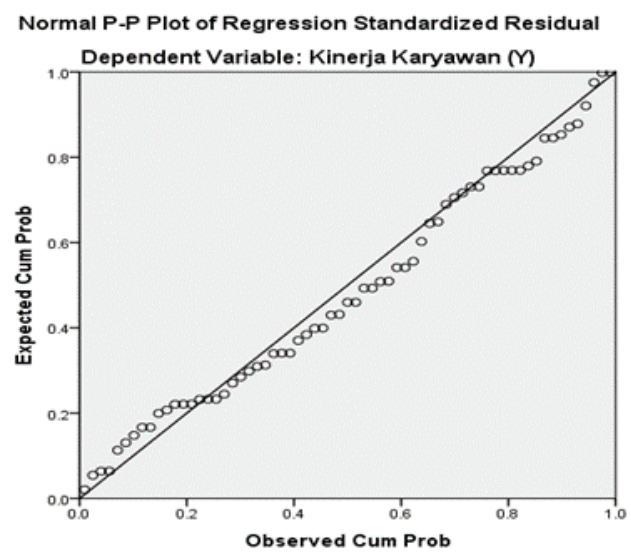

Sumber: Data diolah dengan IBM SPSS

\section{Gambar 2 Hasil Uji Normalitas}

Pada gambar di atas dapat dilihat bahwa grafik normal probability plot menunjukkan pola grafik yang normal. Hal ini terlihat dari titik yang menyebar disekitar garis diagonal dan penyebarannya mengikuti garis diagonal. Oleh karena itu dapat disimpulkan bahwa model regresi memenuhi asumsi normalitas.

\section{Uji Heteroskedastisitas}

Tabel 6. Uji Heteroskedastisitas

Coefficients $^{\mathbf{a}}$

\begin{tabular}{|c|c|c|c|c|c|c|}
\hline \multirow{2}{*}{\multicolumn{2}{|c|}{ Model }} & \multicolumn{2}{|c|}{$\begin{array}{l}\text { Unstandardized } \\
\text { Coefficients }\end{array}$} & \multirow{2}{*}{$\begin{array}{c}\text { Standardized } \\
\text { Coefficients }\end{array}$} & \multirow[t]{2}{*}{$\mathrm{t}$} & \multirow[t]{2}{*}{ Sig. } \\
\hline & & B & Std. Error & & & \\
\hline \multirow{3}{*}{1} & (Constant) & 1.057 & 2.486 & & 0.425 & 0.672 \\
\hline & Kepemimpinan (X1) & -0.065 & 0.066 & -0.159 & -0.987 & 0.328 \\
\hline & Disiplin Kerja (X2) & 0.092 & 0.08 & 0.187 & 1.158 & 0.251 \\
\hline
\end{tabular}

Sumber : Data Primer diolah (2021)

Berdasarkan hasil pengujian pada tabel di atas, glejser test model pada variabel kepemimpinan $\left(\mathrm{X}_{1}\right)$ diperoleh nilai probability signifikansi (Sig.) 0,328 dan disiplin kerja $\left(\mathrm{X}_{2}\right)$ diperoleh nilai probability signifikansi (Sig.) 0,251 dimana keduanya nilai signifikansi (Sig.) > 0,05 . Dengan demikian regression model tidak ada gangguan heteroskesdastisitas, sehingga model regresi ini layak dipakai sebagai data penelitian. 
Tabel 7 Uji Multikolineritas

\begin{tabular}{|c|c|c|c|c|c|c|c|c|}
\hline & \multirow{2}{*}{ Model } & \multicolumn{2}{|c|}{$\begin{array}{l}\text { Unstandardized } \\
\text { Coefficients }\end{array}$} & \multirow{2}{*}{$\begin{array}{c}\begin{array}{c}\text { Standardized } \\
\text { Coefficients }\end{array} \\
\text { Beta }\end{array}$} & \multirow[t]{2}{*}{$\mathrm{t}$} & \multirow{2}{*}{ Sig. } & \multicolumn{2}{|c|}{$\begin{array}{c}\text { Collinearity } \\
\text { Statistics }\end{array}$} \\
\hline & & $\mathrm{B}$ & Std. Error & & & & Tol & VIF \\
\hline \multirow{3}{*}{1} & (Constant) & 9.073 & 3.958 & & 2.292 & 0.025 & & \\
\hline & Kepemimpinan (X1) & 0.334 & 0.105 & 0.369 & 3.178 & 0.002 & 0.607 & 1.647 \\
\hline & Disiplin Kerja (X2) & 0.446 & 0.127 & 0.408 & 3.509 & 0.001 & 0.607 & 1.647 \\
\hline
\end{tabular}

Sumber : Data Primer diolah (2021)

Berdasarkan tabel di atas diperoleh nilai tolerance masing-masing variabel bebas yaitu kepemimpinan 0,607 dan disiplin kerja sebesar 0,607 dimana nilai tersebut kurang dari 1, sedangkan nilai Variance Inflation Factor (VIF) variabel kepemimpinan sebesar 1,647 dan disiplin kerja sebesar 1,647 dimana nilai tersebut kurang dari 10, dengan demikian model regresi ini tidak ada multikolinearitas.

\section{Uji Regensi Linear Berganda}

Tabel 8 Hasil Uji Regresi Linier Berganda Coefficients $^{\mathbf{a}}$

\begin{tabular}{|c|c|c|c|c|c|c|}
\hline & \multirow{2}{*}{ Model } & \multicolumn{2}{|c|}{$\begin{array}{l}\text { Unstandardized } \\
\text { Coefficients }\end{array}$} & \multirow{2}{*}{$\begin{array}{c}\begin{array}{c}\text { Standardized } \\
\text { Coefficients }\end{array} \\
\text { Beta }\end{array}$} & \multirow[t]{2}{*}{$\mathrm{t}$} & \multirow[t]{2}{*}{ Sig. } \\
\hline & & $\mathrm{B}$ & Std. Error & & & \\
\hline \multirow{3}{*}{1} & (Constant) & 9.073 & 3.958 & & 2.292 & 0.025 \\
\hline & Kepemimpinan (X1) & 0.334 & 0.105 & 0.369 & 3.178 & 0.002 \\
\hline & Disiplin Kerja (X2) & 0.446 & 0.127 & 0.408 & 3.509 & 0.001 \\
\hline
\end{tabular}

Sumber : Data Primer diolah (2021)

Berdasarkan hasil perhitungan regresi pada tabel diatas, diperoleh persamaan regresinya $Y=9,073+0,334 X_{1}+0,446 X_{2}$

Dimana: $\mathrm{X}_{1}=$ Kepemimpinan

$$
\begin{aligned}
\mathrm{X}_{2} & =\text { Disiplin Kerja } \\
\mathrm{Y} & =\text { Kinerja Karyawan }
\end{aligned}
$$

1) $9,073=$ Jika Kepemimpinan $\left(X_{1}\right)$ dan Disiplin Kerja $\left(X_{2}\right)=0$ atau konstan, maka Kinerja (Y) akan bernilai 9,073.

2) $0,334=$ Jika Kepemimpinan $\left(X_{1}\right)$ mengalami peningkatan sebesar satu satuan, dan Disiplin Kerja (X2) tetap atau konstan, maka Kinerja (Y) akan mengalami peningkatan sebesar 0,334 kali.

3) 0,446 = Jika Disiplin Kerja $\left(X_{2}\right)$ mengalami peningkatan sebesar satu satuan, dan Kepemimpinan $\left(\mathrm{X}_{1}\right)$ tetap atau konstan, maka Kinerja $(\mathrm{Y})$ akan mengalami peningkatan sebesar 0,446 kali.

\section{Uji Koefisien Determinasi}

Tabel 9. Koefisien Determinasi $X_{1}$ Terhadap $Y$

Model Summary

\begin{tabular}{|c|c|c|c|c|}
\hline Model & $\mathrm{R}$ & $\begin{array}{c}\mathrm{R} \\
\text { Square }\end{array}$ & $\begin{array}{c}\text { Adjusted R } \\
\text { Square }\end{array}$ & $\begin{array}{c}\text { Std. Error of } \\
\text { the Estimate }\end{array}$ \\
\hline 1 & $.625^{\mathrm{a}}$ & 0.391 & 0.381 & 3.047 \\
\hline
\end{tabular}

a. Predictors: (Constant), Kepemimpinan (X1)

Sumber : Data Primer diolah (2021)

Berdasarkan tabel di atas, dapat diketahui bahwa besarnya nilai koefisien determinasi ditunjukkan oleh nilai R Square sebesar 0,391, artinya variabel Kepemimpinan (X1) memiliki kontribusi pengaruh sebesar 39,1\% terhadap Kinerja Karyawan. Sedangkan sisanya 60,9\% dipengaruhi oleh faktor-faktor lain. 
Tabel 10. Koefisien Determinasi $X_{2}$ Terhadap $Y$

Model Summary

\begin{tabular}{|c|c|c|c|c|}
\hline Model & $\mathrm{R}$ & $\mathrm{R}$ Square & $\begin{array}{c}\text { Adjusted R } \\
\text { Square }\end{array}$ & $\begin{array}{c}\text { Std. Error of the } \\
\text { Estimate }\end{array}$ \\
\hline 1 & $.639^{\mathrm{a}}$ & 0.409 & 0.399 & 3.001 \\
\hline
\end{tabular}

a. Predictors: (Constant), Disiplin Kerja (X2)

Sumber : Data Primer diolah (2021)

Berdasarkan tabel di atas, dapat diketahui bahwa besarnya nilai koefisien determinasi ditunjukkan oleh nilai R Square sebesar 0,409, artinya variabel Disiplin Kerja (X2) secara simultan memiliki kontribusi pengaruh sebesar 40,9\% terhadap Kinerja Karyawan. Sedangkan sisanya $59,1 \%$ dipengaruhi oleh faktor-faktor lain.

Tabel 11. Koefisien Determinasi $X_{1}$ dan $X_{2}$ Terhadap $Y$ Model Summary

\begin{tabular}{|c|c|c|c|c|}
\hline Model & $\mathrm{R}$ & R Square & $\begin{array}{c}\text { Adjusted R } \\
\text { Square }\end{array}$ & $\begin{array}{c}\text { Std. Error of } \\
\text { the Estimate }\end{array}$ \\
\hline 1 & $.701^{\mathrm{a}}$ & 0,34167 & 0,32986 & 2.806 \\
\hline
\end{tabular}

a. Predictors: (Constant), Disiplin Kerja (X2), Kepemimpinan (X1)

Sumber : Data Primer diolah (2021)

Berdasarkan tabel di atas, dapat diketahui bahwa besarnya nilai koefisien determinasi ditunjukkan nilai R Square sebesar 0,492, artinya variabel Kepemimpinan dan Disiplin Kerja (X2) secara simultan memiliki kontribusi pengaruh sebesar $49.2 \%$ terhadap Kinerja Karyawan. Sedangkan sisanya 50,8\% dipengaruhi oleh faktor-faktor lain.

\section{Uji Hipotesis \\ Uji Parsial t-test}

Tabel 12 Hasil Uji $\mathbf{t} \mathrm{X}_{1}$ Terhadap Y

Coefficients ${ }^{\mathrm{a}}$

\begin{tabular}{|c|l|c|c|c|c|c|}
\hline \multirow{2}{*}{\multicolumn{2}{|c|}{ Model }} & \multicolumn{2}{|c|}{$\begin{array}{c}\text { Unstandardized } \\
\text { Coefficients }\end{array}$} & $\begin{array}{c}\text { Standardized } \\
\text { Coefficients }\end{array}$ & \multirow{2}{*}{ t } & \multirow{2}{*}{ Sig. } \\
\cline { 3 - 5 } \multicolumn{2}{|c|}{} & B & Std. Error & Beta & & \\
\hline \multirow{2}{*}{1} & (Constant) & 17.382 & 3.445 & & 5.046 & 0,000 \\
\cline { 2 - 6 } & Kepemimpinan (X1) & 0.565 & 0.089 & 0.625 & 6.354 & 0,000 \\
\hline
\end{tabular}

a. Dependent Variabel: Kinerja Karyawan (Y)

Sumber : Data Primer diolah (2021)

Berdasarkan hasil analisis pada tabel di atas diperoleh nilai $t$ hitung $>t$ tabel atau $(6,354$ $>1,998$ ) hal ini diperkuat dengan nilai signifikansi $0,000<0,05$, untuk itu hipotesis pertama yang menyatakan terdapat pengaruh yang positif dan signifikan secara parsial antara kepemimpinan terhadap kinerja karyawan, dapat diterima.

\section{Tabel 13 Hasil Uji t $X_{2}$ Terhadap Y}

Coefficients ${ }^{\mathrm{a}}$

\begin{tabular}{|c|c|r|r|r|r|c|}
\hline \multirow{2}{*}{\multicolumn{2}{|c|}{ Model }} & \multicolumn{2}{|c|}{$\begin{array}{c}\text { Unstandardized } \\
\text { Coefficients }\end{array}$} & $\begin{array}{c}\text { Standardized } \\
\text { Coefficients }\end{array}$ & \multirow{2}{*}{ t } & \multirow{2}{*}{ Sig. } \\
\cline { 3 - 5 } \multicolumn{2}{|c|}{} & \multicolumn{1}{|c|}{ B } & Std. Error & Beta & & \\
\hline \multirow{2}{*}{1} & (Constant) & 12.163 & 4.105 & & 2.963 & 0.004 \\
\cline { 2 - 7 } & Disiplin Kerja (X2) & 0.699 & 0.106 & 0.639 & 6.599 & 0,000 \\
\hline
\end{tabular}

a. Dependent Variabel: Kinerja Karyawan (Y)

Sumber : Data Primer diolah (2021) 
Berdasarkan hasil analisis pada tabel di atas diperoleh nilai $\mathrm{t}$ hitung $>\mathrm{t}$ tabel atau $(6,599>1,998)$ hal ini diperkuat dengan nilai signifikansi $0,000<0,05$, untuk itu hipotesis kedua yang menyatakan terdapat pengaruh yang positif dan signifikan secara parsial antara disiplin kerja terhadap kinerja karyawan, dapat diterima.

\section{Uji Simultan F-test}

\section{Tabel 14 Hasil Uji Simultan}

ANOVAa

\begin{tabular}{|c|l|c|c|c|c|c|}
\hline \multicolumn{2}{|c|}{ Model } & $\begin{array}{c}\text { Sum of } \\
\text { Squares }\end{array}$ & df & $\begin{array}{c}\text { Mean } \\
\text { Square }\end{array}$ & F & Sig. \\
\hline \multirow{3}{*}{1} & Regression & 471.757 & 2 & 235.878 & 29.968 & $.000^{\mathrm{b}}$ \\
\cline { 2 - 7 } & Residual & 487.997 & 62 & 7.871 & & \\
\cline { 2 - 7 } & Total & 959.754 & 64 & & & \\
\hline
\end{tabular}

a. Dependent Variabel: Kinerja Karyawan (Y)

b. Predictors: (Constant), Disiplin Kerja (X2), Kepemimpinan (X1)

Sumber : Data Primer diolah (2021)

Berdasarkan hasil pengujian pada tabel di atas, diperoleh nilai $\mathrm{F}$ hitung $>\mathrm{F}$ tabel atau $(29,968>3,150)$ hal ini juga diperkuat dengan nilai probability signifikansi sebesar $0,000<$ 0,05 . Dengan demikian hipotesis ke tiga yang menyatakan bahwa terdapat pengaruh yang positif dan signifikan secara bersama-sama antara variabel kepemimpinan dan disiplin kerja terhadap kinerja karyawan, dapat diterima.

\section{Kesimpulan}

Berdasarkan hasil analisis data yang telah dilakukan, maka dapat diambil kesimpulan sebagai berikut: Kepemimpinan memiliki pengaruh yang positif dan signifikan terhadap kinerja karyawan sebesar 39,1\%. Dari penguji hipotesis diperlukan nilai $t$ hitung $>t$ tabel $(6,354>1,998)$, hal ini diperkuat dengan probability signifikasi $0,000<0,05$. Dengan demikian H0 ditolak dan $\mathrm{H} 1$ diterima artinya terdapat pengaruh kepemimpinan terhadap kinerja karyawan. Disiplin Kerja memiliki pengaruh yang positif dan signifikan terhadap kinerja karyawan sebesar 40,9\%. Dari pengujian hipotesis diperoleh t hitung $>t$ tabel $(6,599>1,998)$, hal ini diperkuat dengan probability signifikasi $0,000<0,05$, Dengan demikian H0 ditolak dan H2 diterima artinya terdapat pengaruh disiplin kerja terhadap kinerja karyawan. Kepemimpinan dan Disiplin Kerja berpengaruh positif dan signifikan terhadap kinerja karyawan pada bagian Raw Material PT. Distribusi Sentra Jaya - Tangerang Selatan dengan persamaan regresi $Y=9,073+0,334 X 1+0,446 X 2$. Hasil ini menunjukkan koefisien variabel kepemimpinan sebesar 0,334 dan disiplin kerja sebesar 0,446, semua variabel bernilai positif artinya semakin baik kepemimpinan dan disiplin kerja maka semakin baik pula kinerja karyawan. Kontribusi kepemimpinan dan disiplin kerja adalah 49,2\% sedangkan sisanya sebesar $50,8 \%$ dipengaruhi oleh faktor lain. Dari pengujian hipotesis diperoleh $\mathrm{F}$ hitung $>\mathrm{F}$ tabel $(29,968>3,150)$ hal ini diperkuat dengan F-probability signifikasi $0,000<0,05$, dengan demikian $\mathrm{H} 0$ ditolak dan $\mathrm{H} 3$ diterima artinya terdapat pengaruh positif dan signifikan antara kepemimpinan dan disiplin kerja secara simultan terhadap kinerja karyawan.

\section{Daftar Pustaka}

Badeni. (2013). Kepemimpinan dan Perilaku. Bandung : Alfabeta.

Darmadi, D., Suryani, N. L., \& Sari, R. (2021). Pengaruh Budaya Organisasi Dan Disiplin Kerja Terhadap Kinerja Karyawan Di Divisi Likuid Pada PT. Eagle Indo Pharma-Tangerang. Jurnal Arastirma, 1(1), 56-57. Https://Doi.Org/10.32493/Arastirma.V1i1.10062

Darmadi, \& Setiawan, R. (2020). Analisis Implementasi Global Vision Melalui Straregi Pemasaran Perusahaan Roti Maulana Bakery Yang Berimplikasi Pada Daya Saing. Jurnal Ekonomi Efektif, 2(2), 316-325. 
Darmadi, D. (2020). Pengaruh Lingkungan Kerja dan Disiplin Kerja Terhadap Kinerja Karyawan Pada Indomaret Cabang Kelapa Dua Gading Serpong Kabupaten Tangerang. JIMF Jurnal Ilmiah Manajemen Forkamma), 3(3), 240-247. https://doi.org/10.32493/frkm.v3i3.5140

Edy Sutrisno. (2011). Sumber Daya Manusia. Surabaya: PT. Gramedia.

Guruh, M., Syatoto, I., \& Razak, A. (2021). Pengaruh Kepemimpinan Terhadap Kinerja Karyawan Pada PT. Kirana Mitra Abadi Tangerang. Jurnal Arastirma, 1(1), 76-84. Https://Doi.Org/10.32493/Arastirma.V1i1.10064

Kencana, P. N., \& Umaeroh, D. U. (2021). Pengaruh Kepemimpinan Kepala Sekolah Dan Motivasi Terhadap Kinerja Karyawan Pada SMK Puspita Bangsa Ciputat. Jurnal Arastirma, 1(1), 33-42. Https://Doi.Org/10.32493/Arastirma.V1i1.10041

Mangkunegara, P. (2015). Evaluasi Kinerja. Bandung: PT. Refika Aditama.

Noviyanti, I., \& Ramadan, A. S. (2021). Pengaruh Kedisiplinan Dan Kompensasi Terhadap Kinerja Karyawan Pada PT. Mitra Pinanthika Mustika Rent Di Tangerang. Jurnal Arastirma, 1(1), 22-32. Https://Doi.Org/10.32493/Arastirma.V1i1.10039

Shabrina, N., Darmadi, D., \& Sari, R. (2020). Pengaruh Motivasi dan Stres Kerja Terhadap Kinerja Karyawan CV. Muslim Galeri Indonesia. Jurnal Madani: Ilmu Pengetahuan, Teknologi, Dan Humaniora, 3(2), 164-173. https://doi.org/10.33753/madani.v3i2.108

Sugiyono. (2014). Metode Penelitian Kuantitatif, Kualitatif, dan R\&D. Bandung: CV. Alfabeta. 